\title{
Histopathology of cultured sea bream Sparus aurata infected with sanguinicolid trematodes
}

\author{
F. Padrós*, C. Zarza, S. Crespo \\ Biologia Animal (Centre de Referència de Recerca i Desenvolupament en Aqüicultura, Generalitat de Catalunya), \\ Departament de Biologia Animal, de Biologia Vegetal i d'Ecologia, Facultat de Veterinària, \\ Universitat Autònoma de Barcelona 08193, Bellaterra, Barcelona, Spain
}

\begin{abstract}
The present study is the first report of a sanguinicolid infection affecting sea bream Sparus aurata cultured in net cages in the NE of Spain. The disease was associated with trickling mortalities during the cold season (1999 and 2000). Examination of gill wet mounts of the affected population revealed that sanguinicolid infection was present in 82.6 and $100 \%$ of the fish sampled in 1999 and 2000, respectively. Adult flukes, which were located in the kidney, were tentatively identified as members of the family Sanguinicolidae, subfamily Cardicolinae. Eggs and miracidia were found in the gill vascular structures. The inflammatory response triggered by the parasites was moderate and the lesions caused by either eggs and miracidia in the gills or adult flukes in the kidney were not extremely severe, possibly because of the moderate intensity of the parasitosis. Histological observations of sanguinicolid infected sea bream presented here are compared with those reported in other fish species. The role played on sea bream morbility and mortality by other factors (occurrence of a simultaneous moderate monogenean infection, immunological impairement related to low water temperatures) is discussed.
\end{abstract}

KEY WORDS: Sea bream $\cdot$ Sparus aurata $\cdot$ Parasites $\cdot$ Sanguinicolid infection $\cdot$ Histopathology Resale or republication not permitted without written consent of the publisher

\section{INTRODUCTION}

Blood fluke infections are worldwide-spread parasitic diseases that may affect wild and cultured fish (Smith 1997a,b) from both fresh water and the marine environment. In cultured fish, sanguinicolid infections have been associated with serious mortalities (Iqbal \& Sommerville 1986, Ogawa et al. 1989, Crespo et al. 1992) or a decreased growth performance (Iqbal \& Sommerville 1986). According to the extensive review of Smith (1997b) and to the present authors' knowledge, no data on sanguinicolid infections have been reported so far in the sea bream Sparus aurata, one of the most important fish species for Mediterranean aquaculture. The aim of the present work is to report the disease in cultured sea bream and to describe the main histopathological lesions induced in this species by the parasites.

*E-mail: ibiac@blues.uab.es

\section{MATERIALS AND METHODS}

Sea bream Sparus aurata (50 to 400 g body weight) reared in net cages in a fish farm from the NE of Spain suffered chronic low mortalities from December 1998 to April 1999 (0.01 to $0.1 \%$ daily fish losses; water temperature ranging from 12 to $15^{\circ} \mathrm{C}$ ). Impaired growth performance in the affected fish stock was noticed by the farmer and a mild outbreak of winter syndrome was diagnosed in the farm during February. Diseased fish throughout winter (1998-1999) and spring (1999) showed macroscopic gill lesions comprising pallor and, occasionally, white nodules or yellowish necrotic masses at the top of the gill filaments. A total of 23 fish exhibiting these lesions were killed by spinal severance. Fresh skin scrapings and gill wet mounts were examined at the fish farm by light microscopy. Samples from kidney and brain were inoculated onto Blood Agar plates and incubated at $20^{\circ} \mathrm{C}$ for $8 \mathrm{~d}$. Samples of gills, kidney, spleen, liver, heart, digestive tract, mus- 
cle and brain from the same fish were immediately fixed in $10 \%$ buffered formalin. They were then embedded in paraffin, sectioned at 4 to $5 \mu \mathrm{m}$ and stained with haematoxylin-eosin and Gallego trichromic stains for routine light microscopic examination. No parasitological studies were carried out on the material sampled in 1998-1999, and therefore the parasite could not be identified. During the spring months in 2000, 15 fish from the same farm, sampled from a population which had been shown to be by affected by the parasitosis, were investigated for the presence of adult trematodes. After killing the fish as described previously, gill wet mounts were performed and kidney, heart, swimbladder, dorsal aorta and mesenteric blood vessels were carefully dissected under a stereo microscope in petri dishes with saline solution. Parasites obtained following this method were immediately preserved in warm buffered formalin.

\section{RESULTS}

Gill wet mounts of $82.6 \%$ of the fish examined throughout the period 1998-1999 and 100\% of those studied in 2000 revealed the presence of a large num- ber of round to oval ( 35 to $55 \times 35 \mu \mathrm{m}$ ) eggs of sanguinicolid trematodes. These were mainly located along the trailing edge of the gill filament (Fig. 1) and showed a 3 to $6 \mu \mathrm{m}$ thick homogeneous shell that contained 1 living organism. Clusters of eggs could also be observed along the lamellae. The histological study revealed that the shell of these eggs consisted of a thick eosinophilic wall and the inner part was formed by a heterogeneous cellular aggregation (embryo; Fig. 2) or contained more developed forms (miracidia) which exhibited several rows of cilia (Fig. 3). Most eggs were seen within the afferent arteries of the gill filament (Fig. 4) and the vascular arrangement of the lamellae (Figs. 5 \& 6). Some degenerating eggs were also observed trapped in blood vessels, mainly at the base of the gill filaments. In some cases, several lamellae appeared disrupted and small haemorrhages were also seen. A general mild to moderate diffuse inflammatory response involving lymphocytes and granulocytes was noticed. Aggregates of eosinophilic granular cells were occasionally seen surrounding the eggs. No remarkable epithelial hyperplasia was observed in the gills of any of the affected fish examined.

Adult parasites (100 to $150 \mu \mathrm{m}$ in diameter, Fig. 7) were observed in the renal parenchyma (apparently
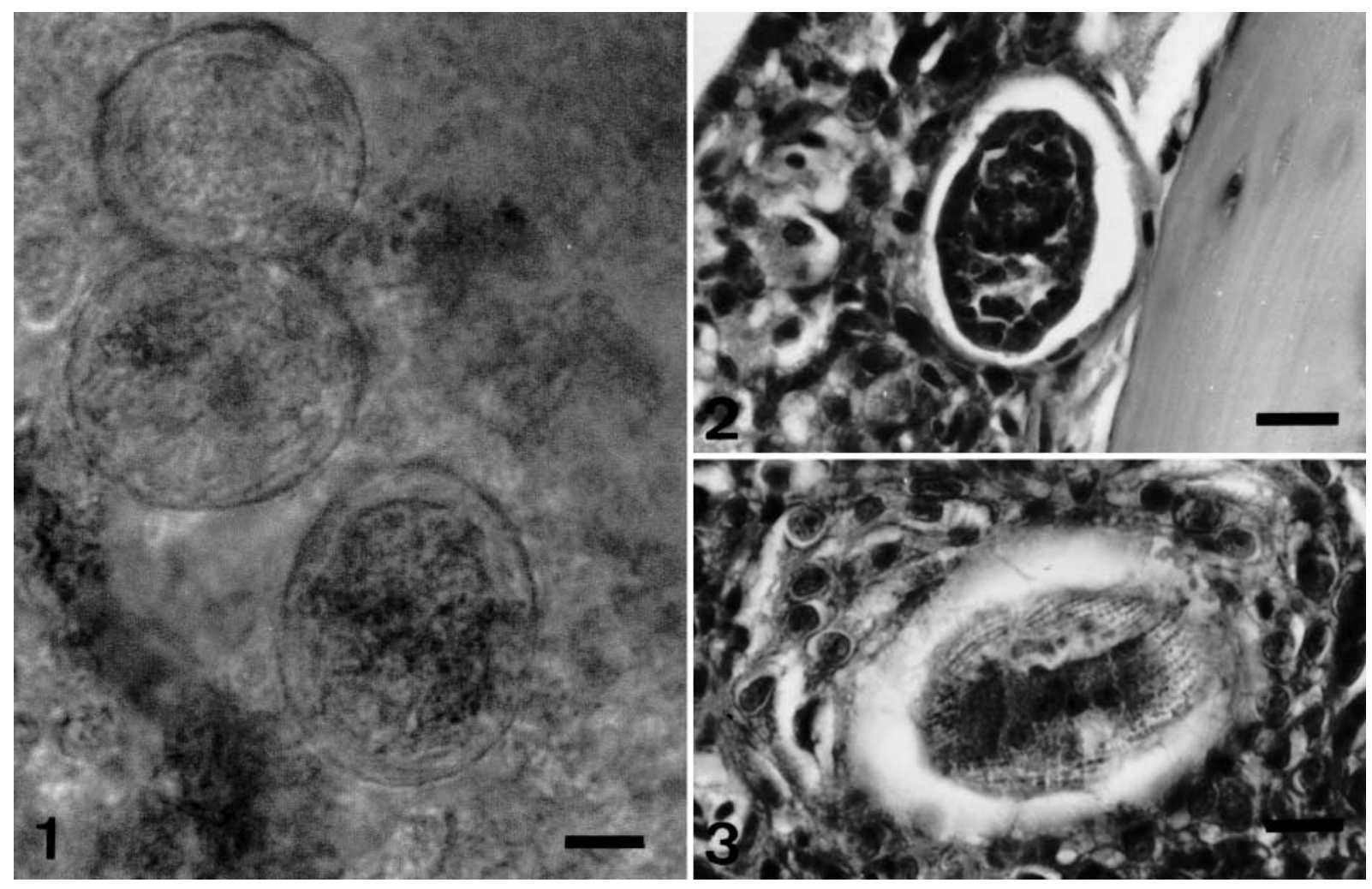

Figs. 1 to 3. Sparus aurata infected with sanguinicolid trematodes. Fig. 1. Oval bodies probably corresponding to eggs of the sanguinicolid trematode in the gill filament observed in a fresh gill mount. Scale bar $=10 \mu \mathrm{m}$. Fig. 2. Sanguinicolid embryo blocked in a gill artery. Scale bar $=10 \mu \mathrm{m}$. Fig. 3. Sanguinicolid miracidia. Note the presence of several rows of cilia. Scale bar $=10 \mu \mathrm{m}$ 
Figs. 4 to 7 . Sparus aurata infected with sanguinicolid trematodes. Fig. 4. Eggs blocked in the afferent arteries of the gill filament. Scale bar $=50 \mu \mathrm{m}$. Fig. 5 . Sanguinicolid eggs located in the gill filament. Scale bar $=50 \mu \mathrm{m}$. Fig. 6. Sanguinicolid egg (arrow) in the tip of a gill lamella. Scale bar $=50 \mu \mathrm{m}$. Fig. 7 . Adult parasite in the kidney. Scale bar $=100 \mu \mathrm{m}$

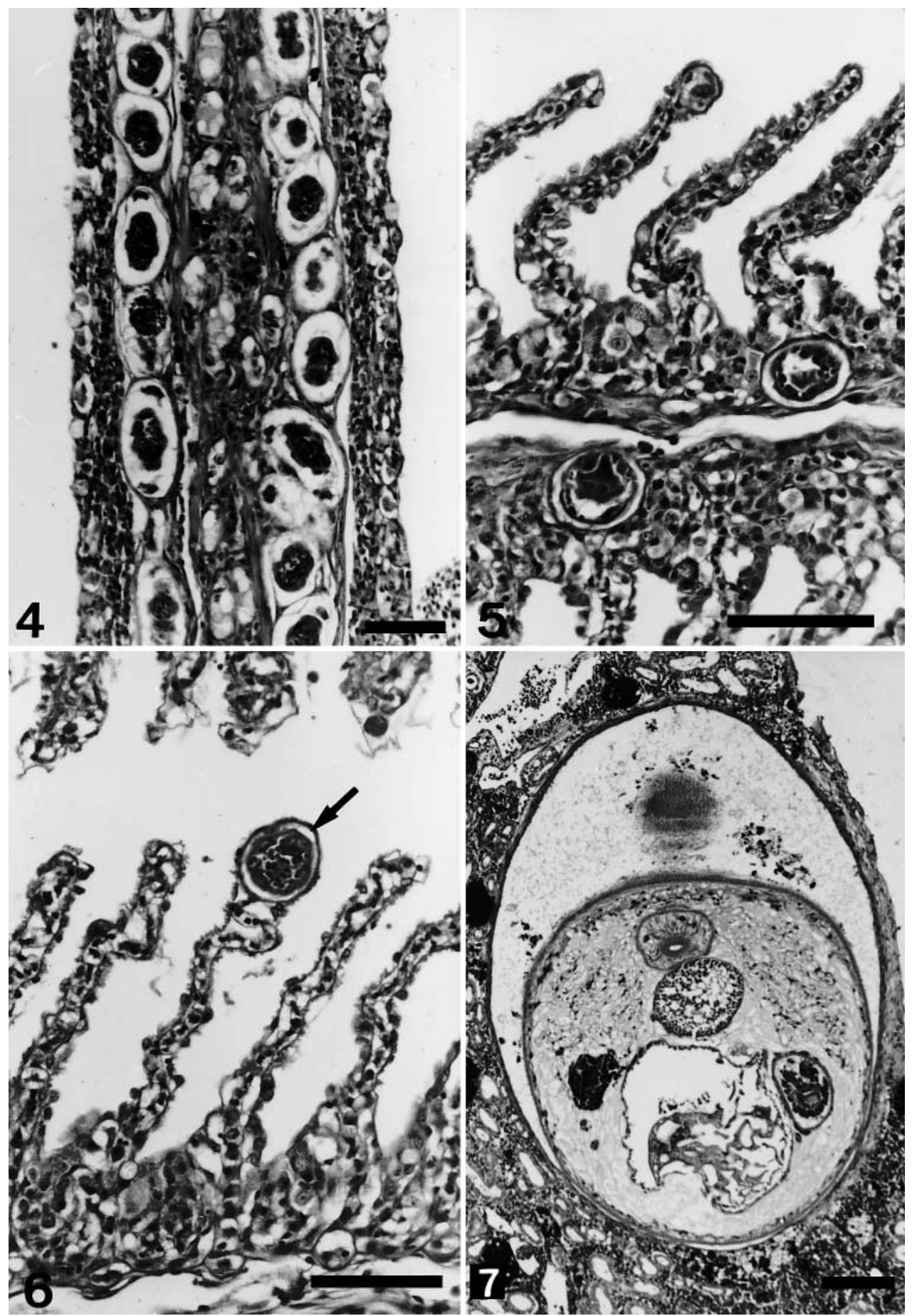

not within blood vessels) of 2 fish caught in 1999 (1 parasite per fish) and were identified as digenean trematodes according to descriptions by Chitwood \& Lichtenfels (1972). Their body was covered by a spiny cuticle, the central matrix being formed by parenchymal cells. Different organs (digestive tract, vitellaria and male and female reproductive organs) were also recognised embedded in the central matrix. A thin fibrocytic capsule was observed around blood flukes. The moderate chronic inflammatory response which these triggered involved mainly melanomacrophages. Granulomata, probably corresponding to reabsorbed parasites, were also found in the renal parenchyma. 


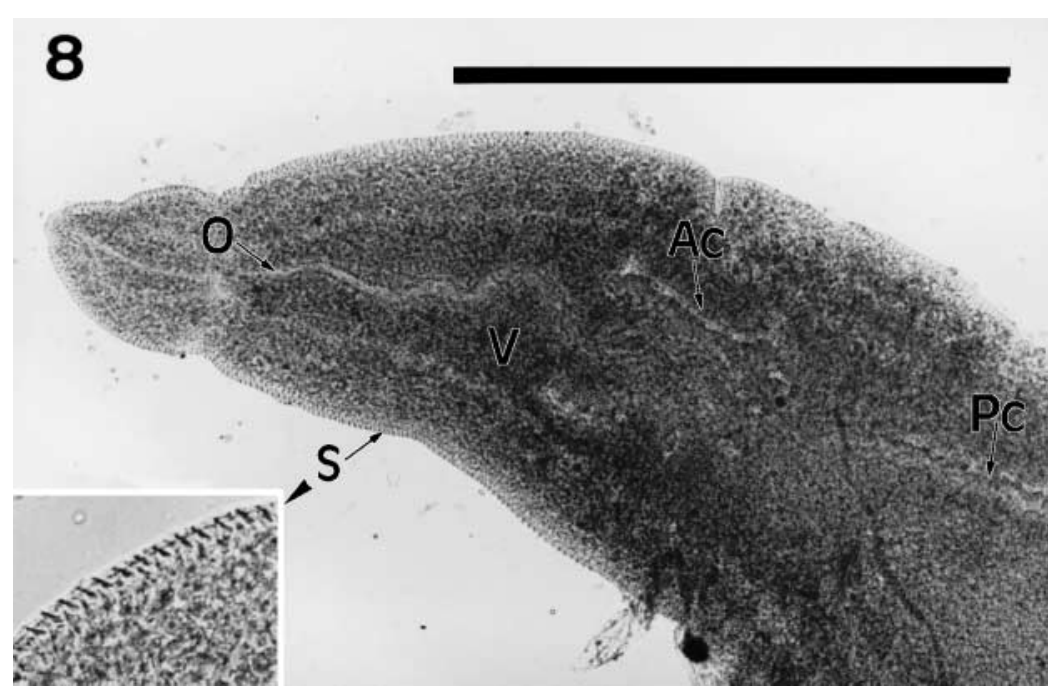

Fig. 8. Adult parasite obtained after kidney dissection and preserved in buffered formalin. Ac: anterior caecum; O: oesophagus; Pc: posterior caecum; S: spines (see detail, left bottom margin); V: vitellaria. Scale bar $=0.5 \mu \mathrm{m}$

\section{DISCUSSION}

The present study is the first report of a sanguinicolid infection in the sea bream Sparus aurata. Our histological data on structure, developmental stages (eggs, ciliated miracidia and adult forms) and location within the host (vascular system) indicate that they are trematodes of the family Sanguinicolidae. Parasitological studies of adults obtained from the kidney identify the parasite as a member of the family Sanguinicolidae which can tentatively be classified into the subfamily Cardicolinae. After the revision of Smith (1997b) there is only one previous description of a sparid species, the jolthead porgy Calamus bajonado, infected by a sanguinicolid parasite Cardicola cardicola, another member of the subfamily Cardicolinae. The low number of adult parasites ob-

Mild inflammatory responses and thrombi were occasionally observed in the endocardium and ventricular cavity of the affected fish although neither eggs nor adult parasites were detected in the heart of any of the fish examined. No obvious pathological alterations in relation to the parasite were observed in the other organs studied and bacteriology was negative.

Although fresh gill mounts from all the fish examined in 2000 indicated the presence of eggs embolized in the gills, only 2 adult parasites were obtained from the dissection of the kidney (Fig. 8). No adult parasites were observed in the other organs and blood vessels examined. Freshly obtained trematodes (1.36 mm body length) showed undulatory movements in the saline solution. They were lanceolated, with spination along their entire body and without suckers. They exhibited a long esophagous, an X-shaped intestine and vitellaria extending throughout most of the body. Ovarian and testicular structures were not well defined from the material obtained in our study. From the morphological features observed, the parasite was tentatively classified into the family Sanguinicolidae and subfamily Cardicolinae according to Yamaguti's (1958) taxonomic criteria.

Although blood fluke eggs were present in the gill filaments of most fish examined, they were not the unique cause of gill lesions since $35 \%$ of the specimens studied in 1999, and $20 \%$ of those examined in 2000 were also mildly to moderately parasitized by monogeneans (mainly Furnestinia echeneis and Microcotyle chrysophrii) and occasionally affected by Flexibacterlike bacteria. tained in our study is not unusual due to their small size and to the fact that they degenerate rapidly (Herbert pers. comm.). Sanguinicolid-infected sea bream cultured in net cages in Spanish facilities showed histopathological lesions similar to those induced by Paradeontacylix spp. in carangids (Seriola purpurascens: Ogawa \& Egusa 1986, Ogawa et al. 1989; $S$. dumerili: Crespo et al. 1992, González et al. 1995, Montero et al. 1999). However, the sea bream inflammatory response against eggs and blood flukes was much lower than that described in the amberjack, possibly because of the higher intensity of the sanguinicolid infection in the latter species (Ogawa et al. 1989, Crespo et al. 1992). Neither extensive hyperplasia of the gill epithelium nor papillate projections in the afferent branchial arteries were observed in the sea bream, which would account for the lower detrimental effect of the pathology in this species.

In the present study, eggs and miracidia were only observed in the gills. However, although we did not find any eggs in the heart, the inflammatory response we described in the endocardic layer of some of the fish examined might indicate the transitory passage of the parasite throughout this organ. Adult flukes were only observed in the kidney. The kidney has been reported to be one of the the main target organs for sanguinicolids (Meade 1967, Herbert et al. 1995, Montero et al. 1999). This notwithstanding, Cruoricola lates has also been described in the mesenteric and pericardial blood vessels and the eye of sea bass Lates calcarifer (Herbert et al. 1995), and Paradeontacylix sp. was found in the heart (Crespo et al. 1992) and caudal vein 
(Montero et al. 1999) of the amberjack Seriola dumerili. Taking into account that in our study we observed a large number of eggs in the gills and adult parasites in only 4 out of 38 sea bream examined, locations other than the kidney cannot be ruled out when a larger sample, including fish of different ages and sampled at different periods of the year, is studied. From our report, the detrimental effect of blood fluke infections on the health status of sea bream is evident although not as severe as in other species. Embolized eggs may induce physical blockage of the blood flow and, consequently, impairment of the gill function. Moreover, hatching of miracidia may cause multiple microlesions and microhaemorrages, which, in turn, might trigger an inflammatory response and result in an anaemic condition of the fish, particularly in the case of a potential massive hatching of the parasites.

However, the specific damage induced by blood flukes to sea bream cannot be thoroughly evaluated since the cause of fish losses was probably multifactorial. A mixed monogenean-Flexibacter-like infection was recorded simultaneously in the sanguinicolid affected sea bream population. Monogeneans have been associated with serious mortalities in Mediterranean cultured fish (Sanz 1992, Christofilogiannis 1993, Álvarez-Pellitero \& Crespo 1995, Padrós \& Crespo 1995) and occurrence of disease syndromes of multifactorial aetiology have been reported worldwide and, particularly, in the Mediterranean basin (Crespo et al. 1994, Álvarez-Pellitero \& Crespo 1995, Tort et al. 1998). In these cases, including the present study, the precise role played by each aetiological agent cannot be accurately elucidated and can be estimated only from the histopathological effects observed.

Although we detected no histopathological lesions associated with Winter Syndrome (Tort et al. 1998) in any of the samples examined and no bacteria were isolated from either the brain or the kidney of affected fish, the effect of cold water temperatures on the immunological status and physiological condition of the fish should also be taken into account when evaluating the pathogenicity of sanguinicolid infection. A higher susceptibility to blood fluke infections during the cold season was also reported in $S$. purpurascens (Ogawa et al. 1989) and Seriola dumerili (Crespo et al. 1992) cultured in Japan and the Mediterranean region-respectively.

Parasites are most prevalent in areas where potential intermediate hosts are abundant. Molluscs have been traditionally described as intermediate hosts for sanguinicolid blood flukes in freshwater. Likewise, in the only known life-cycle amongst the marine sanguinicolid parasites, that of Aporocotyle simplex, a polychaete has been described as the intermediate host (Køie 1982). Periodical net changes and cleaning of cage structures are therefore of great importance to avoid fouling by these invertebrate species which might contribute to the development of the digenean life cycle.

Acknowledgements. We thank Dr Brett Herbert from the Freshwater Fisheries and Aquaculture Centre (Australia) and Dr Juan Gutiérrez Galindo from the Parasitology Unit of the Facultat de Veterinària of the Universitat Autònoma de Barcelona (Spain) for the helpful comments. We also thank the Centre d'Aqüicultura de Sant Carles de la Ràpita (IRTA) for technical support. The present investigation was partially supported by the CIRIT (Comissió Interdepartamental de Recerca i Innovació Tecnològica), Generalitat de Catalunya.

\section{LITERATURE CITED}

Álvarez-Pellitero P, Crespo S (1995) New disease problems in Mediterranean aquaculture. In: Castelló F, Calderer A (eds) Actas del $5^{\circ}$ Congreso Nacional de Acuicultura. Publicacions de la Universitat de Barcelona, Barcelona, p 86-97

Chitwood M, Lichtenfels JR (1972) Identification of parasitic metazoa in tissue sections. Exp Parasitol 32:407-519

Christofilogiannis P (1993) The veterinary approach to seabass and sea-bream. In: Brown L (ed) Aquaculture for veterinarians: fish husbandry and medicine. Pergamon Press, Oxford, p 379-393

Crespo S, Grau A, Padrós F (1992) Sanguinicoliasis in the cultured amberjack Seriola dumerili Risso, from the Spanish Mediterranean area. Bull Eur Assoc Fish Pathol 12:157-159

Crespo S, Grau A, Padrós F (1994) The intensive culture of 0 -group amberjack in the western Mediterranean is compromised by disease problems. Aquacult Int 2:262-265

González G, García A, Jover M, Crespo S (1995) Influence of artificial food on 1+ amberjack (Seriola dumerili, Risso) sanguinicoliasis and epitheliocystis. Bull Eur Assoc Fish Pathol 15:14-16

Herbert BW, Shaharom FM, Anderson IG (1995) Histopathology of cultured sea bass (Lates calcarifer) (Centropomidae) infected with Cruoricola lates (Trematoda: Sanguinicolidae) from Pulau Ketam, Malaysia. Int J Parasitol 25: $3-13$

Iqbal NAM, Sommerville C (1986) Effects of Sanguinicola inermis Plehn, 1905 (Digenea: Sanguinicolidae) infection on growth performance and mortality in carp, Cyprinus carpio L. Aquacult Fish Manag 17:117-122

Køie M (1982) The redia, cercaria and early stages of Aporocotyle simplex Odhner, 1900 (Sanguinicolidae) - a digenetic trematode which has a polychaete annelid as the only intermediate host. Ophelia 21(2):115-145

Meade TG (1967) Life history studies on Cardicola klamathensis (Wales, 1958) Meade and Pratt, 1965 (Trematoda: Sanguinicolidae). Proc Helminthol Soc Wash 34:210-212

Montero FE, García A, Raga JA (1999) First record of Paradeontacylix McIntosh, 1934 species (Digenea: Sanguinicolidae) in Mediterranean amberjack, Seriola dumerili (Risso, 1810), culture. Bull Eur Assoc Fish Pathol 19: 107-109

Ogawa K, Egusa S (1986) Two new species of Paradeontacylix McIntosh, 1934 (Trematoda: Sanguinicolidae) from the vascular system of a cultured marine fish, Seriola purpurascens. Fish Pathol 21:15-19 
Ogawa K, Hattori K, Hatai K, Kubota S (1989) Histopathology of cultured marine fish, Seriola purpurascens (Carangidae) infected with Paradeontacylix spp. (Trematoda: Sanguinicolidae) in its vascular system. Fish Pathol 24:75-81

Padrós F, Crespo S (1995) Proliferative epitheliocystis associated with monogenean infection in juvenile seabream Sparus aurata in the North East of Spain. Bull Eur Assoc Fish Pathol 15:42-44

Sanz F (1992) Mortality of cultured seabream (Sparus aurata) caused by an infection with a trematode of the genus Microcotyle. Bull Eur Assoc Fish Pathol 12:186-188

Smith JW (1997a) The blood flukes (Digenea:Sanguinicolidae and Spirorchidae) of cold-blooded vertebrates, Part 1. A

Editorial responsibility: Wolfgang Körting,

Hannover, Germany review of the literature published since 1971, and bibliography. Helminthol Abs 66(7):255-294

Smith JW (1997b) The blood flukes (Digenea:Sanguinicolidae and Spirorchidae) of cold-blooded vertebrates, Part 2. Appendix I: Comprehensive parasite-host list; Appendix II: Comprehensive host-parasite list. Helminthol Abs 66(7): 329-344

Tort L, Padrós F, Rotllant J, Crespo S (1998) Winter syndrome in the gilthead sea bream Sparus aurata. Immunological and histopathological features. Fish Shellfish Immunol $8: 37-47$

Yamaguti S (1958) Systema helmintum. The digenetic trematodes of vertebrates. Interscience Publishers, Inc, New York

Submitted: February 11, 2000; Accepted: October 12, 2000 Proofs received from author(s): December 29, 2000 